\title{
Depolymerases for Bacterial Exopolysaccharides obtained from Phage-Infected Bacteria
}

\author{
By I. W. SUTHERLAND AND J. F. WILKINSON \\ Bacteriology Department, Edinburgh University
}

(Received 29 December 1964)

\begin{abstract}
SUMMARY
Several bacteriophages have been isolated which, in association with the host bacteria, produce enzymes that depolymerize the exopolysaccharide of Escherichia coli $\mathrm{K} 12$ and other slime polysaccharides of the same chemical type. Chemical analyses show the similarity of the polysaccharides produced by $E$. coli $\mathrm{k12}$, by other $E$. coli strains and by Aerobacter cloacae NCTC 5920 : all contain $28-33 \%$ fucose, 16-19\% glucose, 25-28 \% galactose, 14-22 \% glucuronic acid. The action of the depolymerizing enzymes greatly decreases the viscosity of the polysaccharide solutions but does not liberate any fragments of low molecular weight. Partial purification of the enzymes was achieved by ammonium sulphate precipitation and chromatography on DEAE-cellulose. The enzymes are active against exopolysaccharides produced by bacteria in which the phages are unable to multiply. Evidence is presented to show that the structural genes for enzyme production are located on the phage genome rather than on the bacterial genome. One of the enzyme systems was unusual in that it was only produced following phage infection and lysis of mucoid host strains. Its production was induced by the polysaccharide substrate.
\end{abstract}

\section{INTRODUCTION}

In studying the composition and structure of bacterial and other polysaccharides the use of depolymerizing enzymes can provide a useful adjunct to chemical methods. Enzymes capable of hydrolysing bacterial exopolysaccharides have been obtained mainly from bacterial species isolated by the elective culture technique. Thus Dubos \& Avery (1931) obtained an organism ('Bacillus vulgatus') from which an enzyme that decomposed the capsular polysaccharide of Pneumococcus type III was obtained. Further studies on this, or a very similar system, proved that the enzyme involved was inducible (Torriani \& Pappenheimer, 1962). An alternative source for the isolation of such depolymerases is a bacterium + virulent bacteriophage system. The possibility of obtaining exopolysaccharide depolymerases from such a source was shown by Adams \& Park (1956) who thus isolated an enzyme active against the polysaccharide of Klebsiella pneumoniae $\mathrm{B}$. More recently, bacteriophages which possess enzymes able to break down polysaccharides of Azotobacter vinelandii have been isolated (Eklund \& Wyss, 1962). In our own laboratory enzymes which depolymerize the slime polysaccharide of the A 3 strain of Klebsiella aerogenes type 54 have been obtained from bacteriophage-infected cultures (J. M. Macgregor and J. F. Wilkinson, unpublished results). In an attempt to study the structure of the extracellular slime polysaccharide produced by mucoid strains of 
Escherichia coli $\mathrm{x} \mathbf{1 2}$, enzymes were obtained from phage-infected bacteria. The isolation, partial purification and some properties of these enzymes are now described. A preliminary account of part of this work has already appeared (Sutherland \& Wilkinson, 1964).

\section{METHODS}

Bacteria used. Aerobacter cloacae NCTC 5920 was obtained from the National Collection of Type Cultures, Colindale, London. Escherichia coli $\mathrm{s} 23$ is a galauxotrophic mutant strain of $\mathrm{K} 12$ and was received from Professor E. A. Adelberg (Department of Microbiology, Yale University) as strain AB739. E. coli s53 was a highly mucoid variant of strain $\mathrm{k} 12$ obtained by Dr E. C. R. Reeve (Department of Animal Genetics, Edinburgh University) during screening of mutants for chloramphenicol resistance. $E$. coli $\mathrm{s} 53 \mathrm{C}$ was isolated as a resistant variant of s53 during sensitivity tests with non-depolymerase-producing phages. E. coli $\mathrm{s} 17$ was a mucoid strain obtained from Professor J. P. Duguid (Bacteriology Department, St Andrews University).

Serological typing of these strains at the International Escherichia Centre (Statens Serum Institut, Copenhagen) showed that all were untypable with respect to $\mathrm{O}$-antigens. Strain s53 showed cross-reaction with K30 antiserum and both s53 and $\mathrm{s} 23$ showed $\mathrm{H} 48$ flagellar antigens. Another strain $\mathrm{k} 12$ derivative submitted at the same time had the antigenic formula O102; (K 30); H48. The s 17 strain could not be typed.

Media. Bacteria were normally grown in nutrient broth or on nutrient agar. When maximal exopolysaccharide production was required, a nitrogen-deficient medium was used. It had the following composition (g./l. medium) : yeast extract (Oxoid), 1.0; Casamino acids (Difco, technical), $1.0 ; \mathrm{Na}_{2} \mathrm{HPO}_{4}, 10 \cdot 0 ; \mathrm{KH}_{2} \mathrm{PO}_{4}$, $3.0 ; \mathrm{MgSO}_{4} .7 \mathrm{H}_{2} \mathrm{O}, 0.2 ; \mathrm{K}_{2} \mathrm{SO}_{4}, 1.0 ; \mathrm{NaCl}, 1.0 ; \mathrm{CaCl}_{2}, 0.01 ; \mathrm{FeSO}_{4}, 0.001$. Glucose solution $(20 \%, \mathrm{w} / \mathrm{v})$ was autoclaved separately at $120^{\circ}$ for $15 \mathrm{~min}$. and added to the other components after sterilization to give a final concentration of $2 \%(\mathrm{w} / \mathrm{v})$.

For bacteriophage production, this medium was used in liquid form in $200 \mathrm{ml}$. lots in $500 \mathrm{ml}$. Erlenmeyer flasks. The flasks were aerated by air passed into the medium through sterile Pasteur pipettes. For polysaccharide production the medium was solidified by adding $\mathbf{1 . 5} \%(\mathrm{w} / \mathrm{v})$ New Zealand agar and poured into enamel trays $(40 \times 30 \mathrm{~cm}$.) as a thick layer. The trays were fitted with fairly loose aluminium covers and after uniform inoculation from a liquid culture of bacteria, they were incubated for 3-4 days at $30^{\circ}$.

Bacteriophages. The strains and methods of isolation are described in the text.

Viable counts. Viable counts of bacteria and bacteriophages were made by the method of Miles \& Misra (1938).

Total nitrogen was determined by the micro-Kjedahl technique. The ammonia produced was trapped in boric acid and estimated colorimetrically with Nessler reagent.

Phosphorus. The method of Fiske \& SubbaRow (1925) was used.

Fucose was determined on the unhydrolyzed polysaccharides by the method of Dische \& Shettles (1948).

Glucose and galactose were determined on samples after hydrolysis with $\mathrm{N}_{2} \cdot \mathrm{H}_{2} \mathrm{SO}_{4}$ in sealed ampoules for $8 \mathrm{hr}$. The hydrolysates were neutralized with $\mathrm{BaCO}_{3}$. Glucose 
was determined with glucose oxidase reagent (Boehringer GmbH., Mannheim, Germany) and galactose with galactose dehydrogenase prepared from $\boldsymbol{P}$ seudomonas saccharophila (Doudoroff, 1962).

Uronic acid was determined on the unhydrolysed material by the method described by Bowness (1957).

Paper chromatography of acid hydrolysates of polysaccharides was performed in $n$-butanol + glacial acetic acid + water $(4+1+5$, by vol. $)$ or in the solvent system described by Fischer \& Dörfel (1955). Sugar spots were detected with alkaline silver nitrate or with aniline oxalate.

Concentration of enzyme-containing solutions. Polyethyleneglycol (mol. wt. 6000) was used according to the method of Kohn (1959).

Determination of enzyme activity. This was assayed on old cultures of Escherichia coli $\mathrm{S} 53$ incubated at $30^{\circ}$ for $48 \mathrm{hr}$ on nitrogen-deficient medium and stored at $0^{\circ}$ for at least 7 days before use. The enzyme preparation was diluted in a twofold series in $\mathrm{NaCl}$ containing phosphate buffer $(0.01 \mathrm{M} ; \mathrm{pH} \mathrm{7.2)}$. Drops from calibrated pipettes $(0.02 \mathrm{ml}$.) were carefully placed on the culture surface. The plates were incubated for $2 \mathrm{hr}$ at $37^{\circ}$ and examined for dissolution of polysaccharide. After a further $16 \mathrm{hr}$ at room temperature, the plates were again examined. The enzyme titre was taken to be the highest dilution which gave complete dissolution of the polysaccharide. On occasions a tube test with a $5 \%(\mathrm{w} / \mathrm{v})$ gel of purified polysaccharide was made in the same manner.

Preparation of antisera. The enzyme preparations used in obtaining antisera were high titre eluates from DEAE-cellulose columns. These were injected according to the method described by Adams (1959) for the preparation of phage antisera. The activity of the antisera in inhibiting enzyme action was determined by incubating mixtures of enzyme and suitably diluted serum at $37^{\circ}$ for 20 min., then titrating the mixture in the way described for the enzyme preparations. Controls containing normal rabbit serum were similarly treated.

\section{RESULTS}

\section{The isolation of depolymerase-producing bacteriophages}

The source of all the phages isolated was untreated sewage from Edinburgh sewage works. To each $400 \mathrm{ml}$. sample was added $200 \mathrm{ml}$. sterile broth and $300 \mathrm{ml}$. chloroform. The mixture was then shaken vigorously for several minutes in a screwcapped bottle and then allowed to stand for 3-4 hr at $0^{\circ}$. The clear upper layer was then used for bacteriophage isolation without further treatment.

Nutrient broth cultures $(10 \mathrm{ml}$.) of the potential host bacteria were incubated overnight and then diluted 1/10 with fresh sterile broth and incubated for 1-2 hr at $37^{\circ}$. To this culture was added $1 \mathrm{ml}$. of the sewage preparation and the mixture was incubated overnight at $37^{\circ}$. The culture was centrifuged briefly at low speed to remove most of the bacteria. The supernatant fluid was added to sterile $1 \mathrm{oz}$. screwcapped vials and heated at $60^{\circ}$ for $30 \mathrm{~min}$. to kill remaining host bacteria. A series of tenfold dilutions of this material in sterile saline were made and $\mathbf{0 . 1} \mathbf{m l}$. samples from each dilution spread over nutrient agar plates which had been flooded with a culture of host bacteria and allowed to dry. After incubation for $24 \mathrm{hr}$ at $37^{\circ}$, the plates were examined. Where discrete plaques were visible, material representing 
each plaque type was removed with a sterile needle and inoculated into 1-2 $\mathbf{~ h r}$ cultures prepared as above. These cultures were then treated in exactly the same way as the initial enrichment cultures. After sterilization at $60^{\circ}$, a series of dilutions was again prepared and material spread on agar plates seeded with bacteria. When, after incubation, only one plaque-type was observed, it was assumed that the phage culture was pure. Large amounts of phage for stock cultures were prepared either by the soft agar layer technique (Adams, 1959) or by growth in aerated flask cultures in nitrogen-limited medium.

\section{Host range of the isolated bacteriophages}

Phage preparations $\left(0 \cdot 1 \mathrm{ml}\right.$.) containing $10^{4}$ plaque-forming units (p.f.u.) were added to bacterial lawns and examined after incubation for $24 \mathrm{hr}$ at $37^{\circ}$ for confluent lysis of the bacteria. Sixty strains of Escherichia coli and eight strains of Aerobacter cloacae were tested. Of the $E$. coli strains, 12 were derivatives of strain $\mathrm{k} 12$ and 15 of the remainder were of known serotype. The other strains were obtained from

Table 1. The host range of isolated bacteriophages for Escherichia coli and Aerobacter cloacae

Bacterial susceptibility tested by observation of confluent lysis of strains of $E$. coli and $A$. cloacae grown on solid medium.

\begin{tabular}{|c|c|c|c|c|c|c|c|c|}
\hline \multirow[b]{3}{*}{ Phage } & \multirow[b]{3}{*}{ Origınal host } & \multicolumn{7}{|c|}{ Growth on } \\
\hline & & \multicolumn{5}{|c|}{$\begin{array}{l}E \text {. coli } \\
\text { strains }\end{array}$} & \multicolumn{2}{|c|}{$\begin{array}{c}\text { A. cloacae } \\
\text { strains }\end{array}$} \\
\hline & & $\mathbf{s 2 3}$ & $\mathbf{s 5 3}$ & s 53c & $\begin{array}{c}\text { Other } \\
\text { K12 }\end{array}$ & Others & $\mathbf{5 9 2 0}$ & Others \\
\hline & Escherichia coli & & & & & & & \\
\hline FI & s 53 & + & + & + & + & - & \pm & - \\
\hline F 5, 26, 27 & $\mathbf{s 5 3}$ & + & + & + & + & - & \pm & - \\
\hline F6 & s 23 & + & + & - & \pm & - & - & - \\
\hline & Aerobacter cloacae & & & & & & & \\
\hline F $12,13,14$ & 5920 & - & - & - & - & - & + & - \\
\hline
\end{tabular}

various sources and were selected primarily for ability to produce extracellular polysaccharide, as observed by mucoid growth and negative staining with Indian ink (Duguid, 1951). The A. cloacae strains were all obtained from the National Collection of Type Cultures, Colindale, London. Results of these experiments are shown in Table 1, for some of the phages isolated. All the phages isolated on $E$. coli hosts were specific for $E$. coli $\mathrm{k} 12$ strains. They were avirulent for other strains and, with one exception, for $A$. cloacae. The results for phage $\mathrm{F} 1$ were variable; although it frequently showed confluent lysis on $A$. cloacae 5920, and the numbers of p.f.u. increased when grown in liquid cultures of this organism, negative results were also obtained. The phages isolated on $A$. cloacae $\mathbf{5 9 2 0}$ as host, all appeared to be specific for this strain and had no effect on the other strains of this species which were tested. 


\section{Detection of depolymerase production}

The production of plaques surrounded by a large halo when grown on mucoid bacterial strains is relatively common (Park, 1956). These haloes may be due to the production of exopolysaccharide depolymerase. Alternatively, Reiter \& Oram (1963) suggested that they might be caused by the production of large amounts of phage-associated lysozyme. Initially we selected as possible depolymerase producers those phages which produced plaques surrounded by haloes. These comprised all the phages listed in Table 1, except phage F 6 . To ensure that the haloes were indeed due to depolymerase and not to lysozyme, $1 \mathrm{l}$. volumes of nitrogen-deficient liquid medium were inoculated with host bacteria and each phage species grown in it. The bacteria were removed by centrifugation and the supernatant fluid dialysed against cold running tap water for $16 \mathrm{hr}$. Each preparation was then concentrated to about $10 \mathrm{ml}$. and centrifuged at $10,000 \mathrm{~g}$ to remove particulate material. The resultant supernatant fluids were then titrated for depolymerase activity. All the phages listed, except phage F6, produced enzyme in relatively large amounts. Several phages which did not produce haloes, did not produce depolymerase; phage F 6 was taken as a representative of such species when bacteriophages not producing enzyme were required.

\section{Isolation and partial purification of depolymerases}

Exopolysaccharide depolymerase preparations were obtained from each phage host system, by using phage-infected bacterial cultures grown either by the softagar layer technique or from aerated liquid culture growing in nitrogen-limited medium. The latter method was preferable, since all the medium components could then be removed by dialysis. The whole cultures, after incubation for $8-16 \mathrm{hr}$ at $37^{\circ}$, were centrifuged at $6000 \mathrm{~g}$ in a refrigerated centrifuge; the deposit was discarded. The supernatant fluid was dialysed against cold tap water for $10 \mathrm{hr}$, then concentrated at $0-2^{\circ}$ to about $5 \%$ of the original volume. The concentrated material was dialysed against phosphate buffer $(0 \cdot 02 \mathrm{M} ; \mathrm{pH} \mathrm{7 \cdot 2)}$. Initial fractionation was done by adding saturated ammonium sulphate solution to give a series of fractions between 10 and $90 \%$ saturation, the precipitate at each stage being removed by centrifugation. In all the systems studied almost all the depolymerase-active

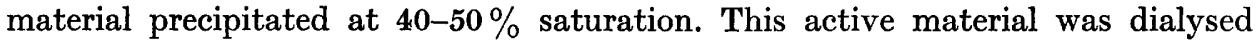
against phosphate buffer $(0.02 \mathrm{M} ; \mathrm{pH} \mathrm{7.2})$ and the dialysis residue then applied to a column of DEAE-cellulose $(12 \mathrm{~cm} . \times 1 \cdot 4 \mathrm{~cm}$.) equilibrated against the same phosphate buffer. A solution of buffer containing an increasing sodium chloride concentration was passed through the column. The enzymically-active material from the phage $\mathrm{F} 1$ and F5 systems, which were most extensively studied, was eluted at a sodium chloride concentration of about $0.1 \mathrm{M}$. These preparations, after concentration and dialysis against the $0.02 \mathrm{M}$-phosphate, were used without further purification.

\section{Substrates for the enzyme(s)}

Crude preparations of the enzyme or enzymes from each phage host system liquefied the exopolysaccharide produced by the host bacterium. They showed equal activity against slime of the same chemical type from other bacteria. Thus depolymerases from the Escherichia coli systems were active against Aerobacter cloacae 
polysaccharide and conversely. The production of a common mucoid substance by several species of the Enterobacteriaceae has been suggested by several authors (Anderson \& Rogers, 1963; Goebel, 1963). Thus the activity of the depolymerase preparations against polysaccharides from a range of bacteria was not unexpected and tends to support the views of these authors.

Escherichia coli strain s53 produced very large amounts of extracellular slime, even when grown on nutrient agar at $37^{\circ}$. This production was very much enhanced by growth at lower incubation temperatures in nitrogen-limited media. Slime was prepared and purified by methods used previously for the slime polysaccharides of Klebsiella aerogenes (Wilkinson, Dudman \& Aspinall, 1955). By these methods, material was prepared from $E$. coli s 53, $E$. coli s17, and Aerobacter cloacae 5920. In each case, paper chromatography of acid hydrolysates showed the presence of glucose, galactose, fucose, glucuronic acid and glucuronolactone in the slimes. The

\section{Table 2. Composition of bacterial extracellular polysaccharides from Escherichia coli and Aerobacter cloacae}

\begin{tabular}{|c|c|c|c|c|c|}
\hline \multirow[b]{3}{*}{ Fucose } & \multicolumn{3}{|c|}{ E. coli strains* } & \multicolumn{2}{|c|}{ A. cloacae } \\
\hline & \multicolumn{5}{|c|}{ Composition $(\%)$} \\
\hline & $\mathbf{3 1} \cdot \mathbf{2}$ & $32 \cdot 8$ & $32 \cdot 7$ & $28 \cdot 0$ & $28 \cdot 3$ \\
\hline Glucose & $19 \cdot 5$ & $19 \cdot 6$ & $16 \cdot 3$ & $16 \cdot 0$ & $17 \cdot 0$ \\
\hline Galactose & $26 \cdot 0$ & $25 \cdot 4$ & $33 \cdot 0$ & $27 \cdot 5$ & $26 \cdot 0$ \\
\hline Glucuronic acid & $20 \cdot 5$ & $18 \cdot 0$ & $17 \cdot 9$ & $13 \cdot 8$ & $22 \cdot 0$ \\
\hline Nitrogen & $0 \cdot 9$ & $0 \cdot 9$ & 0 & $0 \cdot 9$ & $0 \cdot 3$ \\
\hline Phosphorus & $0 \cdot 2$ & $0 \cdot 3$ & 0 & $0 \cdot 2$ & $0 \cdot 2$ \\
\hline
\end{tabular}

* Results of Sapelli \& Goebel (1964). $\quad$ †esults of Dudman \& Wilkinson (1956).

composition of the polysaccharides, after correction for a water content of 15-20\%, is shown in Table 2, with earlier results for A. cloacae 5920 (Dudman \& Wilkinson, 1956) and for the composition of polysaccharide obtained from a capsular variant of $E$. coli $\mathrm{k} 12$ (Sapelli \& Goebel, 1964). It should be emphasized that although $E$. coli strain s53, in our hands, normally produced only slime material, occasional capsulate forms were observed during culture. The selection of such variants was by using phage F6, which by virtue of its inability to produce depolymerase, was unable to penetrate and lyse capsulate bacteria. The capsular material from $E$. coli strain s53C had the same sugar components as the slime polysaccharide when examined by hydrolysis and paper chromatography; a detailed analysis was not made. It can be seen from Table 2 that the compositions of the different preparations were very similar, the greatest difference was in the uronic acid content. However, the methods used for this analysis differed and are probably less satisfactory than those used for estimation of the other sugars. Further evidence of the similarities between the slime polysaccharides of $E$. coli strain s53 and $A$. cloacae 5920 has been obtained by a study of the oligosaccharides produced by partial acid hydrolysis (I. W. Sutherland, unpublished results). 


\section{Effect of depolymerase of phages $F 1$ and F5 on the substrates}

Partially purified depolymerases from the phage F1 and F5 systems were incubated with substrate preparations dissolved in $0.02 \mathrm{M}$-phosphate buffer (pH 7.2) for up to $96 \mathrm{hr}$ at $37^{\circ}$. The most noticeable effect was a decrease in the viscosity of the polysaccharide solution; this was also observed when crude enzyme preparations from other depolymerase-producing phages were used. Examination of the products of enzyme action showed that there was no marked increase in the reducing value of the polysaccharide preparation, so that there was apparently no liberation of reducing sugars or oligosaccharides. This was confirmed by the absence of any detectable diffusate products or dialysis products. Paper electrophoresis and paper chromatography also did not show any products of low molecular weight. After enzymic treatment, two fractions were obtained by ethanol or acetone precipitation. About $75 \%$ of the weight of the original polysaccharide was precipitated by the addition of an equal volume of cold acetone to the solution. The remaining material stayed in solution, was not precipitated by the addition of a further two volumes of acetone; it was obtained as a viscous syrup by per-vaporation and freeze-dried. Chemical analysis did not show any marked differences in the chemical composition of these fractions from that of the original polysaccharide, although when the acetone-soluble fraction was subjected to partial acid hydrolysis there appeared to be a difference in the pattern of oligosaccharides obtained. The phage enzymes showed no activity against several partially characterized oligosaccharides isolated from partial acid hydrolysates of the polysaccharide. The enzymes were inactive against the slime polysaccharide produced by Klebsiella aerogenes type 54, which is known to contain glucose, fucose and glucuronic acid (Wilkinson et al. 1955). Conversely, depolymerases active against this substrate were inactive against Escherichia coli к12 polysaccharide (J. M. Macgregor and J.F. Wilkinson, unpublished results). The depolymerases thus show a substrate specificity. Whether this depends on the presence of certain repeating units in the polysaccharide substrate must await structural studies on the substrates.

It is of interest that the depolymerase specificity was not necessarily correlated to the phage specificity. Thus enzymes from Aerobacter cloacae + phage systems were active against the Escherichia coli polysaccharide and conversely. The depolymerases were also active against the polysaccharide produced by $E$. coli $\mathrm{s} 17$, a strain in which none of the phages was capable of multiplication.

\section{The effect of the host bacterium on enzyme production}

In the case of all the depolymerase-producing phages except F1, growth in a susceptible bacterium was accompanied by enzyme production. Phage F1, when grown on Escherichia coli strain s53 (slime-producing), produced depolymerase, which was also detected following its growth in Aerobacter cloacae 5920. However when phage $\mathrm{F} 1$ was grown in $E$. coli strain s 23 , a non-mucoid $\mathrm{K} 12$ derivative, no depolymerase was detected. This suggested that in the phage F $1+$ bacterial host system, the depolymerase was induced by the presence of the substrate, i.e. the slime polysaccharide. When purified polysaccharide from $E$. coli strain s53 was sterilized as a $1 \%(\mathrm{w} / \mathrm{v})$ solution at $100^{\circ}$ for $90 \mathrm{~min}$. and added to culture medium to a final concentration of $0.5 \%(\mathrm{w} / \mathrm{v})$, growth of $E$. coli strain s 23 in this medium, 
followed by infection with phage F 1, led to depolymerase production. However, the quantity of enzyme was less than that obtained from comparable culture in $E$. coli strain s 53. Addition of the acetone-soluble product of enzyme action to the medium followed by bacterial and phage culture, did not lead to depolymerase production. Attempts to show depolymerase production in the absence of phage infection were unsuccessful. Thus, ultrasonic treatment of bacteria taken at different stages of growth never gave preparations which caused dissolution of slime polysaccharide.

\section{The effect of depolymerase on bacterial infection}

Since the substrates for the phage depolymerase enzymes are normally slime polysaccharides, i.e. do not occlude the bacterial surface, it was not at first possible to determine the effect of the enzymes on infection of bacteria by phage. However, a capsulate variant of Escherichia coli s53, designated s53c, was obtained. This variant was resistant to phages such as $\mathbf{F} 6$ which did not produce depolymerase. It was susceptible to all the coliphages which produced depolymerase. Titration of the phages on susceptible hosts showed that where the phage system resulted in depolymerase production, the phage titres obtained on slime- or capsule-forming host bacteria and on non-mucoid bacteria were very similar. No plaques were observed following addition of non-depolymerase-producing phages to capsulate host bacteria. It is probable that small amounts of depolymerase, sufficient to permit entry to capsulate bacteria, were present in close association with the phage particles. This is implied from the observation that many phage preparations which contained no detectable enzyme, as determined by titration, were still able to multiply in cultures of $E$. coli s $53 \mathrm{c}$.

It was also found that the purified depolymerase of phages F1 or F5 had little or no effect on bacterial viability. To a culture of susceptible bacteria in broth was added $0.1 \mathrm{ml}$. of purified enzyme preparation with a titre of $256 / \mathrm{ml}$. Samples were withdrawn after various periods of incubation at $37^{\circ}$ and bacterial counts made. As a check on the sterility of the enzyme preparations, phage titrations were also made but no plaques were observed. Counts of bacterial colonies from the cultures to which depolymerase had been added differed little from control cultures without added enzyme.

\section{Antisera to depolymerase and to host bacteria}

In an attempt to determine whether the production of depolymerase was controlled by the bacterial or the bacteriophage genome, the effect of antisera on purified depolymerase preparations of phages F1 and F5 was examined. The addition of homologous antiserum resulted in complete inhibition of depolymerase activity but antiserum to phage $\mathrm{F} 1$ enzyme did not inhibit phage $\mathrm{F} 5$ depolymerase and conversely. Antisera to Escherichia coli s53 and to other $\boldsymbol{E}$. coli strains did not inhibit any of the phage depolymerases. This would seem to indicate that production of the depolymerases is controlled by the phage genome. In gel diffusion tests in agar, a line of precipitation was obtained between the depolymerase preparation and homologous antiserum, but not with antisera to the host bacteria. 


\section{Other properties of the depolymerases}

Ultracentrifugation of purified depolymerase preparations for prolonged periods at $100,000 \mathrm{~g}$ in a Spinco model $\mathrm{L}$ preparative ultracentrifuge resulted in no deposition of enzymically active material. Sterilization by filtration through Oxoid membranes resulted in little loss of activity.

A depolymerase isolated by Adams \& Park (1956) from phage-Klebsiella aerogenes systems was notable for the fact that the enzyme was more heat stable than was the phage with which it was associated; $10 \%$ of the enzyme activity remained after exposure to $70^{\circ}$ for $30 \mathrm{~min}$. In our enzyme systems, all measurable activity was destroyed after $5 \mathrm{~min}$. at $70^{\circ}$. During the same time, the phage titre on a nonmucoid bacterial host decreased from $1 \cdot 8 \times 10^{8}$ to $2 \cdot 0 \times 10^{7}$. It continued to decrease thereafter until no viable phage was detectable after $45 \mathrm{~min}$. at $70^{\circ}$. At $65^{\circ}$, the enzymes were also rapidly inactivated and although the phage titre was decreased there was still considerable phage activity remaining after $60 \mathrm{~min}$. The results of a typical experiment with phage F1 titrated on Escherichia coli s 23 are shown in Table 3. Exposure of the phage enzymes to $\mathrm{pH}$ values above $7 \cdot 5$ and below 6.0 also resulted in rapid loss of activity. For this reason, all heat inactivation experiments were done in 0.05 $\mathrm{M}$-phosphate buffer ( $\mathrm{pH} 7 \cdot 0)$.

\section{Table 3. The effect of heating at $65^{\circ}$ on $F 1$ phage and depolymerase titre}

Samples of phage $\left(5 \mathrm{ml}\right.$.) held in tubes in a water bath at $65^{\circ}$ and samples $(0.1 \mathrm{ml}$.) withdrawn at intervals and titrated on bacterial lawns on nutrient agar and old mucoid lawns on nitrogen-deficient medium respectively.

$\begin{array}{rcc}\text { Time (min.) } & \text { Phage titre p.f.u. } & \text { Depolymerase titre } \\ 0 & 6 \cdot 2 \times 10^{11} & 32 \\ 15 & 5.9 \times 10^{10} & 4 \\ 30 & 9 \cdot 0 \times 10^{9} & 0-2 \\ 45 & 5.0 \times 10^{9} & 0 \\ 60 & 4 \cdot 3 \times 10^{9} & 0\end{array}$

\section{DISCUSSION}

A number of exopolysaccharide depolymerases produced by phages in association with bacteria are now known. While some properties may be common to all such systems, there are also marked differences. Thus, Adams \& Park (1956) reported that a depolymerase for Klebsiella pneumoniae polysaccharide was produced in all susceptible hosts. Although we obtained similar results for most of the Escherichia coli phages isolated, there was one exception. The results with $E$. coli $\mathrm{k} 12+$ bacteriophage F1 system indicated that this depolymerase is probably inducible, the presence of the substrate polysaccharide being required for enzyme production. This phage $\mathbf{F} 1$ differed in that the other depolymerase-producing phages isolated by us caused enzyme production in mucoid and in non-mucoid bacterial hosts.

The inducibility of the $\mathrm{F} 1$ enzyme is of interest in deducing a role for the depolymerase. Unlike the Klebsiella pneumoniae or Azotobacter systems studied by Adams \& Park (1956) and Eklund \& Wyss (1962), respectively, the Escherichia coli strains used in the present study were slime-producing but non-capsulate. The bacterial surface of such organisms is not occluded by polysaccharide and the presence of 
polysaccharide-decomposing enzyme would not be essential to enable a phage particle to reach and absorb to the bacterial surface. However, the presence of large aggregates of slime might be a sufficient hindrance to prevent many of the phage particles from reaching and infecting their hosts. The presence of a depolymerase would therefore confer an advantage on such phages, in that they would disperse the protecting polysaccharide and reach the bacterial surface.

Adams \& Park (1956) found that the depolymerase for Klebsiella pneumoniae polysaccharide was in two forms. One of these was a freely diffusable protein, while the second was attached to or firmly associated with the phage particles. Our methods were not sufficiently sensitive to permit detection of the second form. Its presence would seem likely from the observation that phage preparations with no detectable enzyme were nevertheless able to infect capsulate Escherichia coli organiisms. Thus infection of a few bacteria, followed by lysis and release of free depolymerase, might allow the second generation of phage particles to infect a high proportion of the remaining bacteria.

The question arises as to whether the structure of the depolymerase is determined by the bacterial genome or by a structural gene of the phage. Since attempts to obtain depolymerase from the uninfected host bacteria were unsuccessful, it would seem that the production of the enzyme requires the presence of host bacteria and phage. Further, the hypothesis that the effect of phage was merely to enhance the production of an existing bacterial enzyme would appear to be discounted by the serological evidence. The enzymes were only inhibited by homologous antiserum and not by antisera to other depolymerases or to the host bacteria. In other words, the antigenic specificity of the depolymerase was determined by the nature of the phage rather than the host.

The mode of action of the depolymerases remains obscure. The lack of diffusible products following enzyme action, together with the very marked decrease in viscosity, would suggest that some internal linkage is broken, although the products of this cleavage must still be relatively large. The linkage may be one which is acidstable, since enzymic hydrolysis followed by partial acid hydrolysis of the polysaccharides showed a much more complex pattern of oligosaccharides than did acid hydrolysis alone (I. W. Sutherland, unpublished results). The depolymerase for Klebsiella pneumoniae polysaccharide was found by Adams \& Park (1956) to yield no detectable small molecular weight products after hydrolysis, nor did it cause an increase in the reducing value of the polysaccharide preparation. Further, the hydrolysis products retained their serological specificity, indicating that the endgroup sugars were probably unaffected by the enzyme.

The relative insensitivity of methods of depolymerase assay used prevent a thorough study of the kinetics of enzyme formation following phage infection of the bacteria. Such studies must await elucidation of the substrate structure and the development of improved assay methods. The substrate of these depolymerases is of interest in that it appears to be produced by Escherichia coli strains and also by certain other species of the Enterobacteriaceae. This confirms the suggestions of several workers that different members of the Enterobacteriaceae may produce mucoid material of similar if not identical composition. These substances have been termed Mantigens (Ørskov, Ørskov, Jann \& Jann, 1963) or colanic acid (Goebel, 1963). The $E$. coli polysaccharide can be produced either as a capsule or as free slime. There 
was no detectable difference in the capsular and slime polysaccharides, confirming the results previously obtained using Klebsiella aerogenes type 54 (Dudman \& Wilkinson, 1955).

The authors wish to thank Miss Jane Evans, Mr J. Fitchie and Mr J. D. Caird for their technical assistance.

\section{REFERENCES}

Adams, M. H. (1959). In Bacteriophages, p. 504. New York: Interscience.

Adams, M. H. \& Park, B. H. (1956). An enzyme produced by a phage-host cell system.

II. The properties of the polysaccharide depolymerase. Virology, 2, 719.

Anderson, E. S. \& Rogers, A. H. (1963). Slime polysaccharides of the Enterobacteriaceae. Nature, Lond., 198, 714.

Bowness, J. M. (1957). Application of the carbazole reaction to the estimation of glucuronic acid and glucose in some acidic polysaccharides and in urine. Biochem. J. 67, 295.

Dische, Z. \& Shetrles, L. B. (1948). A specific colour reaction of methylpentoses and a spectrophotometric micromethod for their determination. J. biol. Chem. 175, 595.

Doudoroff, M. (1962). Meth. Enzymol. 5, 399.

Dubos, R. \& Avery, O. T. (1931). The decomposition of the capsular polysaccharide of pneumococcus type III by a bacterial enzyme. J. exp. Med. 54, 51.

Dudman, W. F. \& Wilkinson, J. F. (1956). The composition of the extracellular polysaccharides of Aerobacter-Klebsiella strains. Biochem. J. 62, 289

Duguid, J. P. (1951). The demonstration of bacterial capsules and slime. J. Path. Bact. $63,673$.

Duguid, J. P. \& Wilkinson, J. F. (1953). The influence of cultural conditions on polysaccharide production by Aerobacter aerogenes. J. gen. Microbiol. 9, 174.

EkLund, C. \& WYss, O. (1962). Enzyme associated with bacteriophage infection. J. Bact. 84, 1209.

Fischer, F. G. \& Dörfel, H. (1955). Die papierchromatographische Trennung und Bestimmung der Uronsäuren. Hoppe Seyl. Z. 301, 224.

Fiske, C. H. \& SubbaRow, Y. (1925). The colorimetric determination of phosphorus. J. biol. Chem. 66, 375.

Goebel, W. F. (1963). Colanic acid. Proc. nat. Acad. Sci., U.S.A., 49, 464.

KонN, J. (1959). A simple method for concentrating fluids containing protein. Nature, Lond., 183, 1055.

Miles, A. A. \& Misra, S. S. (1938). The estimation of the bactericidal power of the blood. J. Hyg., Camb., 38, 732.

Ørskov, I., Ørskov, F., J JNN, B. \& J JNN, K. (1963). Acidic polysaccharide antigens of a new type from $E$. coli capsules. Nature, Lond., $200,144$.

Park, B. H. (1956). An enzyme produced by a phage-host cell system. I. The Properties of a Klebsiella phage. Virology, $2,711$.

Reiter, B. \& Oram, J. D. (1963). Group N streptococcal phage lysin. J. gen. Microbiol. 32, 29.

SAPELL, R. V. \& GoEBEL, W. F. (1964). The capsular polysaccharide of a mucoid variant of E. coli K12. Proc. nat. Acad. Sci., U.S.A., 52, 265.

Sutherland, I. W. \& Wilkinson, J. F. (1964). Exopolysaccharide depolymerase produced by phages in association with Escherichia coli $\mathrm{K} 12$. J. gen. Microbiol. 34, xii $P$.

Torriani, A. \& Pappenheimer, A. M. (1962). Inducible polysaccharide depolymerases of Bacillus palustris. J. biol. Chem. 237, 3.

Wilkinson, J. F., Dudman, W. F. \& Aspinale, G. O. (1955). The extracellular polysaccharide of Aerobacter aerogenes a 3 (sl) (Klebsiella type 54). Biochem. J. 59, 446. 